\title{
Fault Detection and Localization using Continuous Wavelet Transform and Artificial Neural Network Based Approach in Distribution System
}

\author{
Himadri Lala ${ }^{1}$, Subrata Karmakar ${ }^{1}$ and Sanjib Ganguly ${ }^{2}$ \\ ${ }^{1}$ Department of Electrical Engineering, NIT Rourkela, Rourkela, Odisha-769008, India \\ ${ }^{2}$ Department of Electronics and Electrical Engineering, IIT Guwahati, Assam-781039, India \\ karmakar.subrata@gmail.com
}

\begin{abstract}
This article presents an advanced continuous wavelet transform (CWT) based approach for fault detection and localization in distribution systems using the artificial neural network (ANN). In this study, CWT extracts distinct features from the transient signals captured from the bus. The derived features are utilized to train and test appropriate ANN architecture in different stages to detect and localize the faults. The proposed scheme provides an optimum method for classification as well as localization of the various kinds of fault with different source short circuit (SSC) level in different locations. The whole detection and localization process consists of several stages. In the first stage, it detects faulty feeder. The faulty line is identified in the second stage. Finally, in the third stage, fault type and fault location are being calculated from the relaying point. The performance of the proposed CWTANN based approach is quite promising as compared to traditionally used algorithms. However, a correlation-based feature selection technique is also implemented to reduce training time and improve accuracy. This algorithm is tested in $11 \mathrm{kV}$ radial Indian distribution network but can be applied in other distribution networks also.
\end{abstract}

Keywords: Continuous Wavelet Transform, Artificial Neural Network, Fault localization, Fault Detection, Unsymmetrical fault, Distribution system.

\section{Introduction}

The rapidly growing demand for electric power leads to interconnection in power systems. With the increasing number of interconnections between power systems, it becomes more and more complicated [1]. The most important role of all the power system engineers is to ensure utmost reliability and continuity of service. It is also essential to reduce the repair time and speed up the system restoration after a fault. The outage time of power increases due to old fault detection and localization techniques [2]-[6]. It causes massive workforce and time wastage. Although there are few types of equipment exist in the substations, which designed to detect and localize the faults, do not always give an accurate result. Therefore, it is highly needed to identify the faults and its exact location, so that system restoration process becomes faster. It is not feasible to avoid the natural hazards, accidents, and dis-operation of power system equipment. The fault causes transients in distribution systems, which are not easy to identify because of their short duration. The instrument for measuring the transient are ought to have a high sampling rate to give accurate precision in portraying transient conditions concerning their amplitude and frequency content. These qualities are fundamental for performing a transient investigation.

In the power system literature, CWT based approaches are applied to detect and localize faults in the past [2]. However, there are different other methodologies for investigating power system transients. The expert systems [7], fuzzy based systems [8], various optimization techniques [9], ANN [10], different wavelet transform methods [11], etc, are the various favourite techniques. All of the above methodologies suffer from higher computational time, lack of robustness and accuracy in performance. Unlike Discrete wavelet transform (DWT) few researchers applied CWT [12] for detection [13] of distribution system faults. The CWT is one of the most useful techniques in analyzing system transients along with soft computing

Received: March $27^{\text {th }}, 2018$. Accepted: June $23^{\text {rd }}, 2018$

DOI: $10.15676 /$ ijeei.2018.10.2.1 
technologies. In [3] D. Thukaram et al. proposed a fault detection and localization technique using principle component analysis (PCA) as an extractor of distinct attributes and support vector machine (SVM) and ANN as the classifier and estimation tool. This method is an impedancebased method. The error in location estimation is nearly around $10 \mathrm{~m}$. In the past several years, different researchers have proposed various fault-location estimation techniques. Mirzaei et al. [14] and Mora et al. [15] Saha et al. [16] reviewed different methods of localizing faults such as impedance-based, frequency, and knowledge-based methods. According to Mirzaei et al., highfrequency based method along with knowledge-based methods gives a much accurate result in fault localization. In continuation of previous literature, Yadav et al. [17] applied DWT and ANN to localize fault in double circuit transmission line. It gives accuracy, which is not much higher in some cases, and in the distribution network, this algorithm is not tested. In the [18], Saleh et al. implemented a DWT based dynamic voltage restorer in a distribution system. Whereas, Samantaray et al. proposed combined H-S transform and ANN based fault localizer [19] in power transmission system. As in distribution network, previous localization results are lesser accurate, or the methods of estimation are complex which results in increasing calculation or computational time and indeed increases the complexity of the system. Zhang et al. suggested a discernible signal analysis for distribution system [20] ground faults, but the main shortcoming of the scheme is that it cannot eliminate the consequences of high impedance fault. Yong et al. Proposed a DWT based method to identify the type of fault in the distribution system [21]. However, Lovisolo et al. have attempted to detect and localize the fault which causes voltage sag and swell [22]. The results provide accurate detection of the fault, but it gives relatively low fault localization accuracy (85\%). In [23] a CWT-ANN based detection and localization algorithm is applied on a hybrid distributed generation systems. The results regarding fault localization are encouraging, but it needs to be optimized and implemented in a distribution system. The overall scenario of fault detection and localization algorithm stands on two basic pillars, i.e. signal processing and soft computing techniques. The various signal processing techniques are well tested. But the soft computing techniques are not the well tested approaches. The main reason of not using soft computing techniques for this kind of problems are its blackbox type nature. The various techniques like fuzzy, ANN, SVM and various optimization techniques have their own unique and excellent capabilities. But, alone they cannot fulfil the requirements of fault detection and localization. However, ANN has the capability of both classification and estimation. Further, if ANN combines with feature selection, data-mining and optimization techniques, it can become the most efficient one for solving fault detection and localization problems.

In this work, a multistage CWT-ANN based time-frequency domain analysis is proposed to detect and localize fault much accurately as compared to the previous literature of fault classification and localization in the distribution system regarding very less error in localization and classification in lesser computational time. A 52-bus radial distribution network is considered as a test system. Different types of fault are simulated in different fault locations with different source short circuit (SSC) level to obtain the transient signals. The CWT is used to process these signals and features are extracted from the signal, which after that used in training and testing with ANN for fault classification and localization. This work also consists of a qualitative comparison of results with related articles. The novelties of this work are as follows.

- Cross-validation analysis along with ANN is used for classification to give much reliable output.

- In case of fault localization CWT along with ANN is performing well in localizing faults as the error in testing is in the range, which is reasonably good in comparison with previous works.

- Considering different dynamically changing loading conditions classification and localization accuracy found to be reasonably good. 


\section{Fault Detection and Localization Algorithm using CWT and ANN}

Power system fault classification and localization algorithm mainly consist of two tools: (i) wavelet transform (WT) and (ii) ANN. Fast Fourier transform (FFT) response of any fault signal describes that fault transient signals are non-stationary as so many higher order harmonics are there along with the fundamental frequency. Thus, in this scenario, FFT can give the frequency response of the signal but cannot provide the time information of the spectrum. To solve this problem signals are processed with CWT. The extracted features using CWT needs to be utilized in classification and estimation. Several techniques are there such as fuzzy logic, SVM, ANN, etc. Among all the soft computing techniques ANN is selected after comparing the capabilities of the other tools for this particular problem.

\section{A. Continuous Wavelet Transform (CWT)}

In mathematics, a square integral of orthonormal series is represented by a wavelet. Presently a day, WT is famous amongst the researcher for time-frequency domain analysis. Fourier analysis transforms a signal into sinusoids with different frequencies. Similarly, WT splits up the signal and coefficients are generated by scaling and shifting of 'mother wavelet.' Therefore, non-stationary signals can be better represented with the class of irregular signals rather than with sinusoids. At the end of the transformation, wavelet gives the correlation coefficient which provides a time-frequency interpretation of a signal [12], [24]-[27].

Consider the functions obtained by shifting and scaling a "mother wavelet" $\Psi_{c}(t) \mathrm{L}_{2}(\mathrm{R})$.

$$
\Psi_{a, b}(t)=\frac{1}{|a|} \Psi\left(\frac{t-b}{a}\right)
$$

Where ' $a$ ' corresponds to scale or frequency band, b corresponds to time or translation, which normalizes the energy across the different scale. The normalization ensures that $\|\Psi \mathrm{a}, \mathrm{b}(\mathrm{t})\|=$ $\|\Psi(\mathrm{t})\|$. If the admissibility condition is satisfied then,

$$
c_{\Psi}=\int_{-\infty}^{\infty} \frac{|\Psi(\omega)|^{2}}{|\omega|} \mathrm{d} \omega<\infty
$$

As the admissibility condition gives an opportunity that $\Psi(0)=0$ (from discrete Fourier transform) due to sufficient decay in $\Psi(\omega)$ which is Fourier transform of $\Psi(\mathrm{t})$ :

$$
\int_{-\infty}^{\infty} \Psi(\mathrm{t}) \mathrm{dt}=\Psi(0)=0
$$

The wavelet has band-pass behaviour. To avail unit energy, wavelet has to be normalized. So,

$$
\|\Psi(\mathrm{t})\|^{2}=\int_{-\infty}^{\infty}|\Psi(\mathrm{t})|^{2} \mathrm{dt}=\frac{1}{2 \pi} \int_{-\infty}^{\infty}|\Psi(\omega)|^{2} \mathrm{~d} \omega=1
$$

As $\left\|\Psi_{a, b}(\mathrm{t})\right\|^{2}=\|\Psi(\mathrm{t})\|^{2}=1$. The CWT of function $\mathrm{f}(\mathrm{t}) \in \mathrm{L}_{2}(\mathrm{R})$ is defined as:

$$
\begin{gathered}
\mathrm{CWT}_{\mathrm{f}}(\mathrm{a}, \mathrm{b})=\int_{-\infty}^{\infty} \Psi_{\mathrm{a}, \mathrm{b}}(\mathrm{t}) \mathrm{f}(\mathrm{t}) \mathrm{dt}=\left\langle\Psi_{\mathrm{a}, \mathrm{b}}(\mathrm{t}) \mid \mathrm{f}(\mathrm{t})\right\rangle \\
F_{R M S}=\sqrt{\frac{|C W T(f, a, b)|^{2}}{L_{S}}}
\end{gathered}
$$

Here, the $F_{R M S}$ and $L_{S}$ stand for RMS of CWT coefficients and number of coefficients respectively.

\section{B. Training \& Testing of ANN Algorithm}

ANN is a tool by which an intelligent system is made with fast decision-making capabilities. This work includes two type of ANN algorithm [28][29]. In type 1 ANN is used as classifier along with the data mining technique cross-validation. Whereas in type 2 , ANN acts as an estimator.

\section{Classification algorithm (Cross-Validation)}

Cross-Validation $(\mathrm{CV})$ is a machine-learning algorithm, which splits entire dataset into two parts: first one used for training and the second one used for testing of the model. Crossvalidation makes cross-over training and validation sets in such a way that in a successive round each data gets a chance to get validated. This way of validating the data is commonly called cross-validation algorithm. 
For example, if, $\left\{\chi_{\mathrm{i}} \mathcal{T}_{i} \mathcal{V}_{\mathrm{i}}\right\}$ is the whole data set, training, and validation sets of fold $i$ respectively. Here, the 'fold' stands for the number of training and validation sets. Therefore, K-fold crossvalidation divide $X$ into $\mathrm{k}$ number of sets. If, $i=1, \ldots, K$, the respective training and validation sets can be illustrated in the manner given below in equations.

$$
\begin{array}{cl}
\mathcal{V}_{1}=\chi_{1} & \mathcal{T}_{1}=\chi_{2} \cup \mathcal{X}_{3} \cup \cdots \cup \mathcal{X}_{\mathrm{K}} \\
\mathcal{V}_{2}=\chi_{2} & \mathcal{T}_{2}=\chi_{1} \cup \chi_{3} \cup \cdots \cup \mathcal{X}_{\mathrm{K}} \\
\vdots & \\
\mathcal{V}_{\mathrm{K}}=\chi_{\mathrm{K}} & \mathcal{T}_{\mathrm{K}}=\chi_{1} \cup \chi_{2} \cup \cdots \cup \mathcal{X}_{\mathrm{K}-1}
\end{array}
$$

Here, $V_{1}, V_{2}, V_{3} \ldots \ldots . V_{\mathrm{k}}$ represents the validation set for each fold and the $\mathcal{T}_{1}, \mathcal{T}_{2}, \mathcal{T}_{3} \ldots . . \mathcal{T}_{\mathrm{k}}$ represents training sets for different sets folds. The whole algorithm runs through different iterations (no of folds). The final validation accuracy of the data set is determined by the averaging the validation output of the different folds. In this work, 10-fold cross-validation is applied on the CWT coefficients calculated from the fault signal for classification.

\section{Fault localization using ANN}

The fault localization algorithm requires a machine learning technique with estimation and prediction property in it. The attributes are calculated from the fault signal are utilized to train the proper neural architecture in MATLAB [15] environment. The "Levenberg-Marquardt" training algorithm is used for the training purpose. The neural network model used in this work is called multilayer perceptron. It computes the weighted sum of the network inputs for each neuron. If this sum is greater than the threshold value, it generates an output ' $y$ ', which is explained in Eqn. 7. Eqn. 8 gives the output where ' $f$ ' is the step activation function calculated from Eqn. 9. Therefore, the total no of the element is $(n+1)$ for ' $n$ ' incoming signals.

$$
\begin{aligned}
& S U M=\sum_{i=1}^{n} X_{i} W_{i} \\
& Y=f\left(\sum_{i=1}^{n} X_{i} W_{i}\right) \\
& f(x)=\left\{\begin{array}{lll}
1 & \text { if } & x>0 \\
0 & \text { if } & x \leq 0
\end{array}\right.
\end{aligned}
$$

\section{Flowchart and Description of the Proposed Approach}

The proposed scheme for fault classification and localization is shown in Figure. 1 and Figure. 2. When a fault occurs in the system, the algorithm at first detects the feeder in which the fault has occurred. In the next step, it will detect the faulty line. The response from the sending end of the faulty line then used for fault detection and determining fault location. Thus proposed methodology achieves the accuracy in analyzing fault type and location in the distribution system. In this work, CWT - ANN based algorithm is used for fault classification and localization on a 52 - bus distribution system in different stages. The Figure. 1(a) describes the process of the faulty feeder and faulty line detection, i.e., in which feeder the fault occurred and in which line.

To begin with, measurement of current signals from all the feeder and lines are taken. Further, the current signals from three feeders are processed using CWT with 'coiflet3', "Daubechies4", and "morlet" mother wavelet and in proper scales. The RMS of the coefficients obtained by applying CWT then classified using ANN (cross-validation) algorithm to find the faulty feeder. Once, the faulty feeder is found, the similar approach is taken for finding out the faulty line. Here, the current signals from each bus of the faulty feeder are considered for the faulty line detection using the same CWT-ANN based approach. As the faulty line is detected, RMS of CWT coefficients of the faulty line current signal is taken for the classification of fault. Similar to the faulty feeder and line detection, cross-validation technique is used for the fault type identification. On the other hand, the same CWT coefficients are put in the FFNN for the localization of fault. 


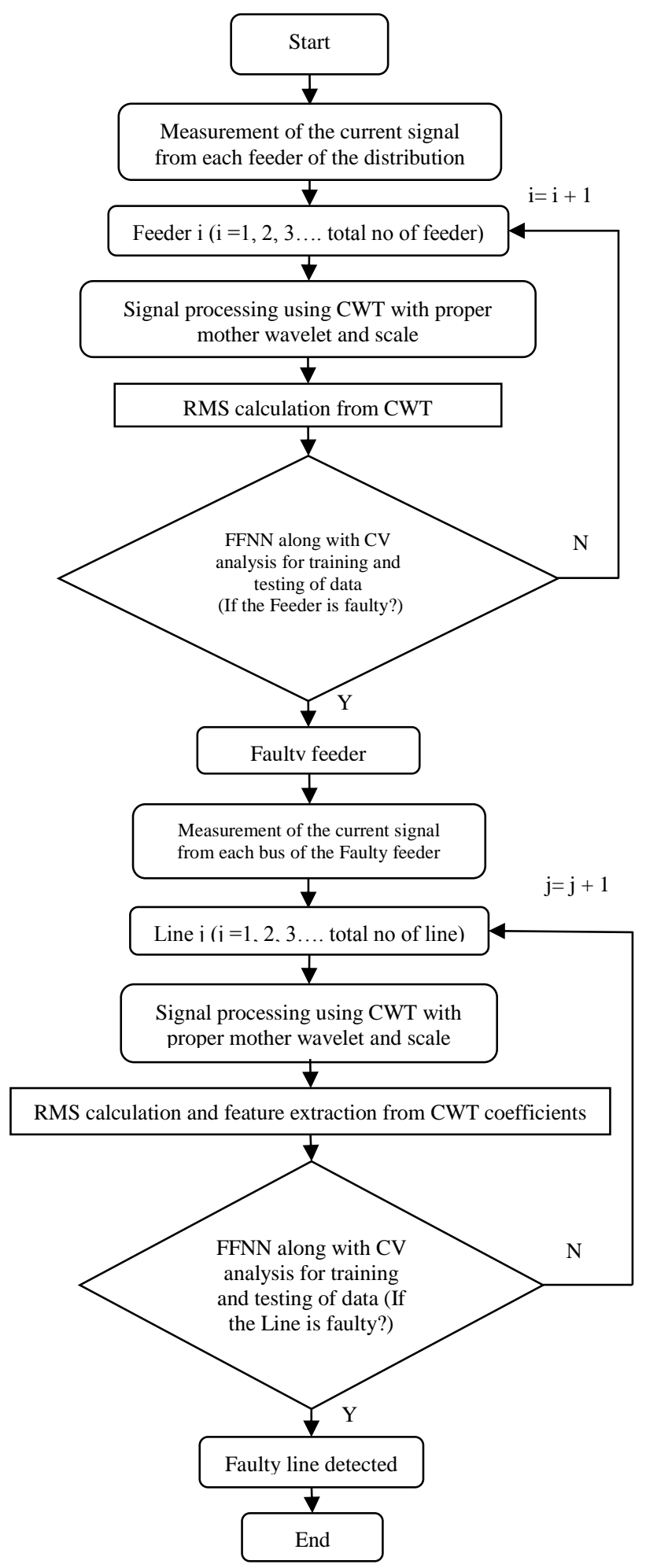

(a) 


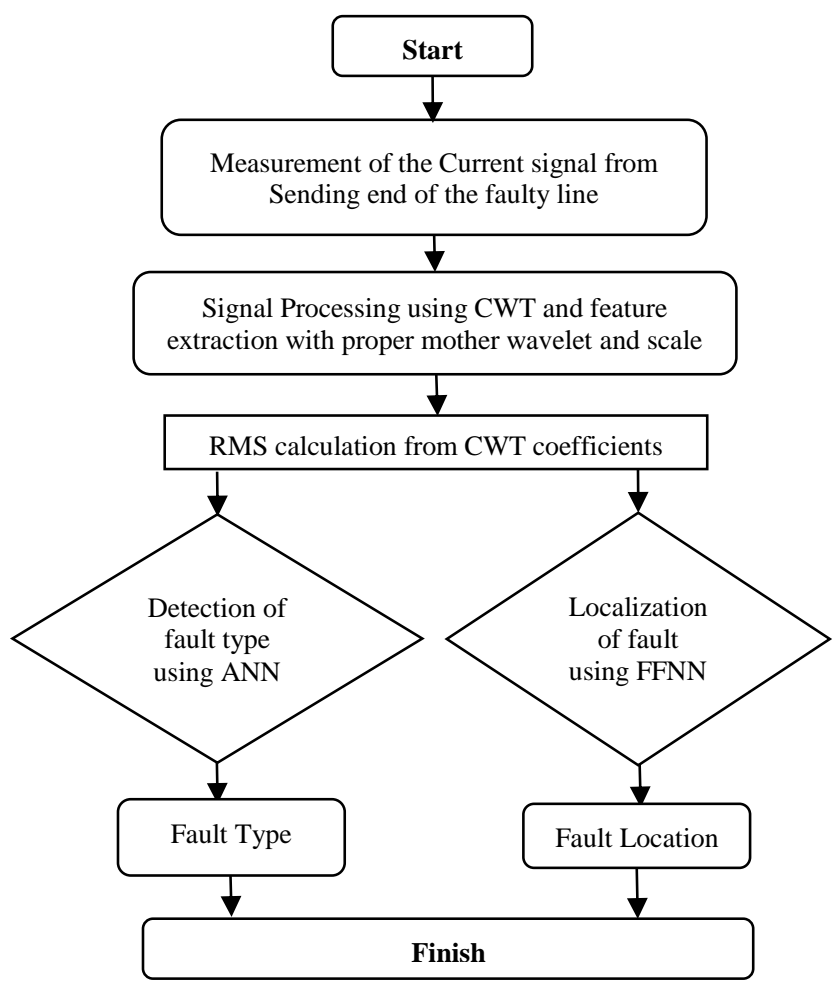

(b)

Figure 1. Fault detection and localization process flow diagram; (a) Faulty feeder and line detection, (b) Fault type identification and fault localization.

The best neural architecture for fault localization is obtained after several rounds of training. In Figure. 1 (b) fault type detection and fault localization process are shown. In this three-stage detection and localization of faults, CWT is used as signal processing tool and ANN for machine learning. A brief description of various steps of the whole fault detection and localization are presented below:

- 52-bus $11 \mathrm{kV}$ radial distribution system is modelled in MATLAB-SIMULINK.

- Fault data with SSC level: 20, 25, 30, 35, 40, 45, and 50 MVA and four different types of fault are acquired with a sampling frequency of $50 \mathrm{kHz}$.

- Signal processing using CWT with 'coiflet3', "Daubechies4", and "morlet" mother wavelet and in proper scales.

- The RMS values of the CWT coefficients are calculated.

- The faulty feeder detection is done with the features obtained from feeder end using crossvalidation and ANN.

- The faulty line detection is done with features obtained from different buses of the faulty feeder using cross-validation and ANN.

- Fault type detection and fault localization are done with the features obtained from the sending end currents of the faulty line using cross-validation and ANN respectively.

The configurations of the test system are Base kVA: $1000 \mathrm{kVA}$, Base voltage: $11 \mathrm{kV}$, Type of the conductor used: ACSR, Resistance of any line: $0.0086 \mathrm{pu} / \mathrm{km}$, Reactance of any line: $0.0037 \mathrm{pu} / \mathrm{km}$. All the simulations are performed here on a PC with Intel Core i7-3770 processor, which has a processor speed of $3.40 \mathrm{GHz}$. 


\section{Simulation Results and Analysis}

In this study, a 52-bus practical Indian network is considered for fault detection and localization. The 52-bus distribution network is modelled with MATLAB-SIMULINK to simulate the system. Line and load data can be obtained from [3]. The 52 bus test system is shown in Figure. 2. In Figure. 2 "line 2-3" is shown as a fault line.

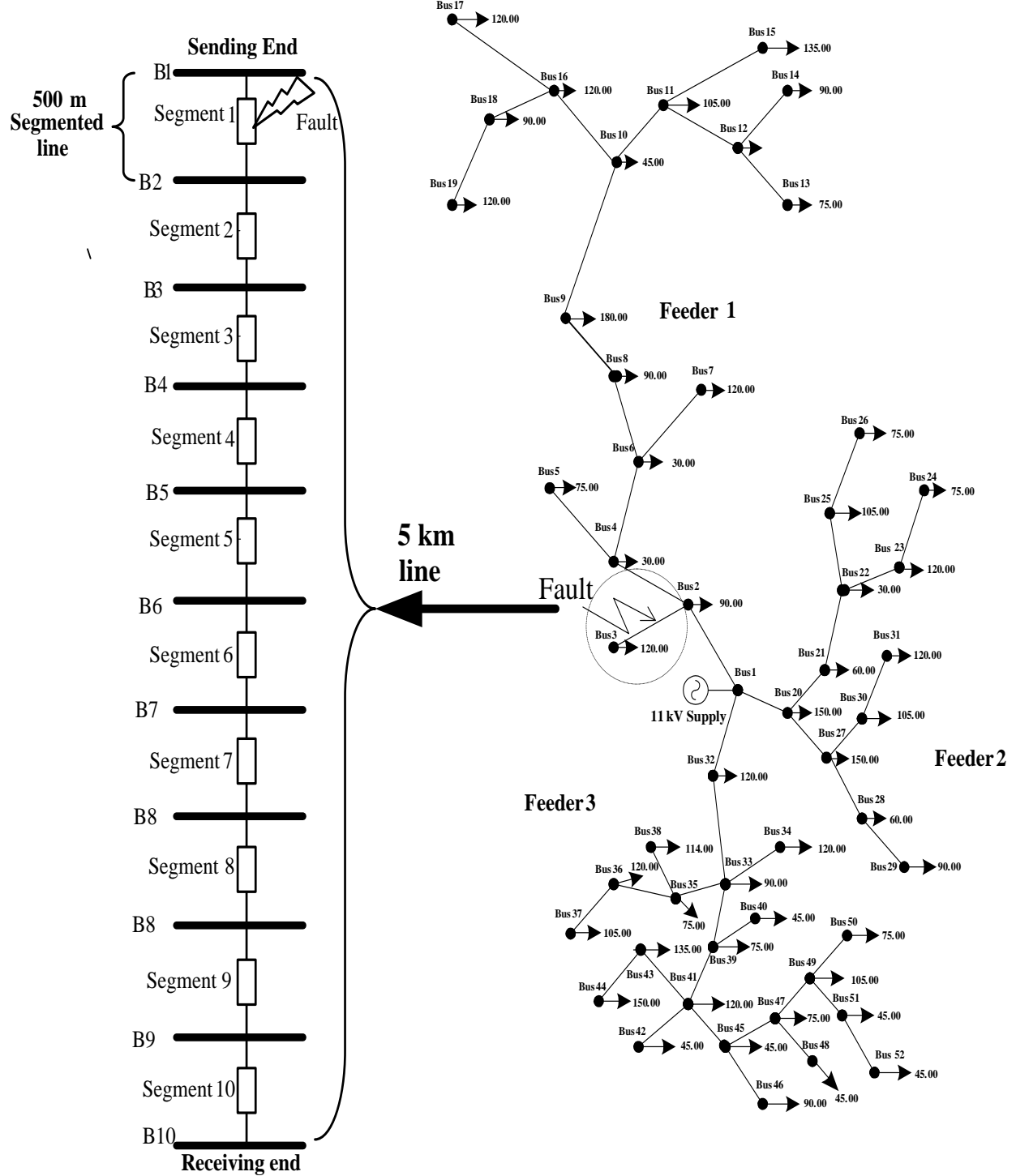

Figure 2. 52 bus test system and segmentation of Line 2-3[9]

For fault detection, different conditions are simulated. The sampling frequency of $50 \mathrm{kHz}$ is taken for the sampling of single end current signals. The captured signals then processed with CWT. The attributes are computed from the processed data. The attributes calculated are supplied to ANN for fault classification and localization.

- Simulation is done with SSC level: 20 MVA to 50 MVA.

- Different fault locations: 10, 20, 30, 40, 50, 60, 70, 80, 90, and 100 percent of the line from sending end.

Among three feeders, the tests are performed on line 2-3 (the line between bus-2 and bus-3). This line is $5 \mathrm{~km}$ long, and it is further segmented into ten parts, each equivalent to $500 \mathrm{~m}$ of line. 
The Line segment model is shown in Figure. 2. These line segments represent different locations of a particular line. On this line, different types of faults are simulated in 10 different locations with 20, 25, 30, 35, 40, 45 and 50 MVA source short-circuit level to build the training set. All the measurements are taken from sending end (node B1 in Figure. 2 segmentation model) of the line. Some of the three-phase current signals obtained from bus-2 is shown in Figure. 3 (a)-(d) which correspond L-G (line to ground) fault, L-L-G (double line to ground) fault, 3ph-G (3phase to ground) fault, and L-L (line to line) fault, respectively. These transient signals need to be processed in time-frequency domain for extracting the information. In this study, the CWT is selected as a signal-processing tool.
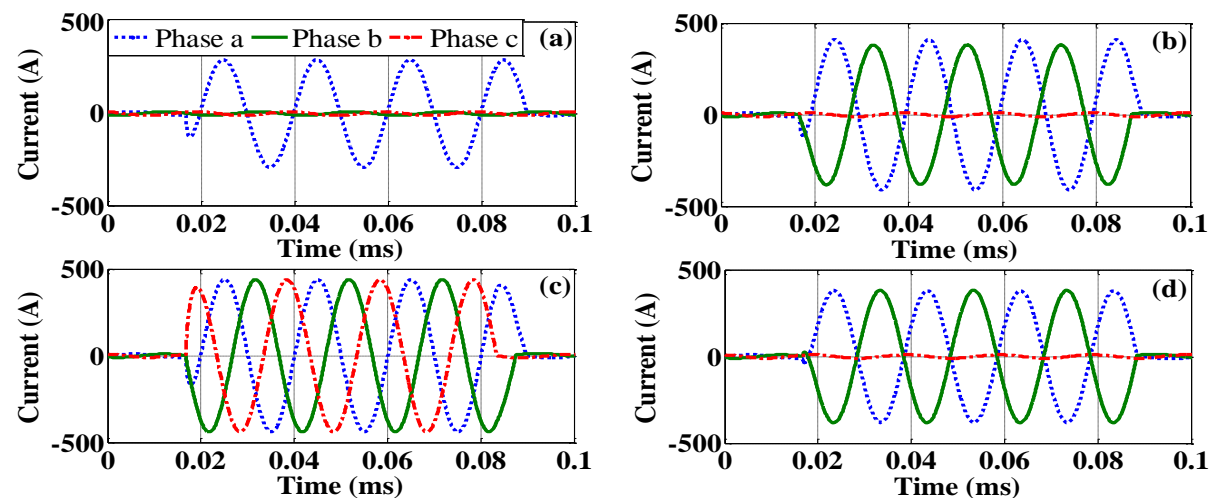

Figure 3. 3-phase current waveform captured from 52-bus radial distribution system for the different type of fault; (a) 3-phase current waveform for L-G fault, (b) 3-phase current waveform for L-L-G fault, (c) 3-phase current waveform for 3ph-G fault, (d) 3-phase current waveform for L-L fault.

Various signal-processing tools such as FFT, short time Fourier transform (STFT) and wavelet, etc. are available which can perform frequency or time-frequency domain analysis. However, the transient signals for faults are non-stationary. The FFT is only suitable for stationary signals, as it does not carry the time information. On the other hand, the STFT provider a time-frequency transformation but it has a resolution problem due to its fixed window length. The CWT eliminates all the shortcomings of STFT and becomes a much favourite signalprocessing tool to be used for fault transient analysis.

\section{A. Mother-Wavelet and Scale Selection}

The frequency domain response of the fault current signals indicates the presence of third harmonics. Therefore, to implement CWT, proper mother wavelet and scale selection is the most important thing to be taken care of. After applying 'scalogram' technique on various mother wavelets such as 'coiflet3', 'Daubechies4', and 'morlet' etc. the proper scales are selected to analyze the third harmonics in the current signal. The selected scale for "coiflet3" mother wavelet is 234, 235, 236, 247 and for "Daubechies4", the appropriate scales are 237, 238, 239, 240. Whereas, the scales selected for 'morlet' wavelet transform are 270, 271, 272, and 274. Therefore, from 3-phase fault current signals captured from different nodes, the CWT coefficients are obtained. Different source short-circuits level and fault location are considered for four different predominant fault types. 

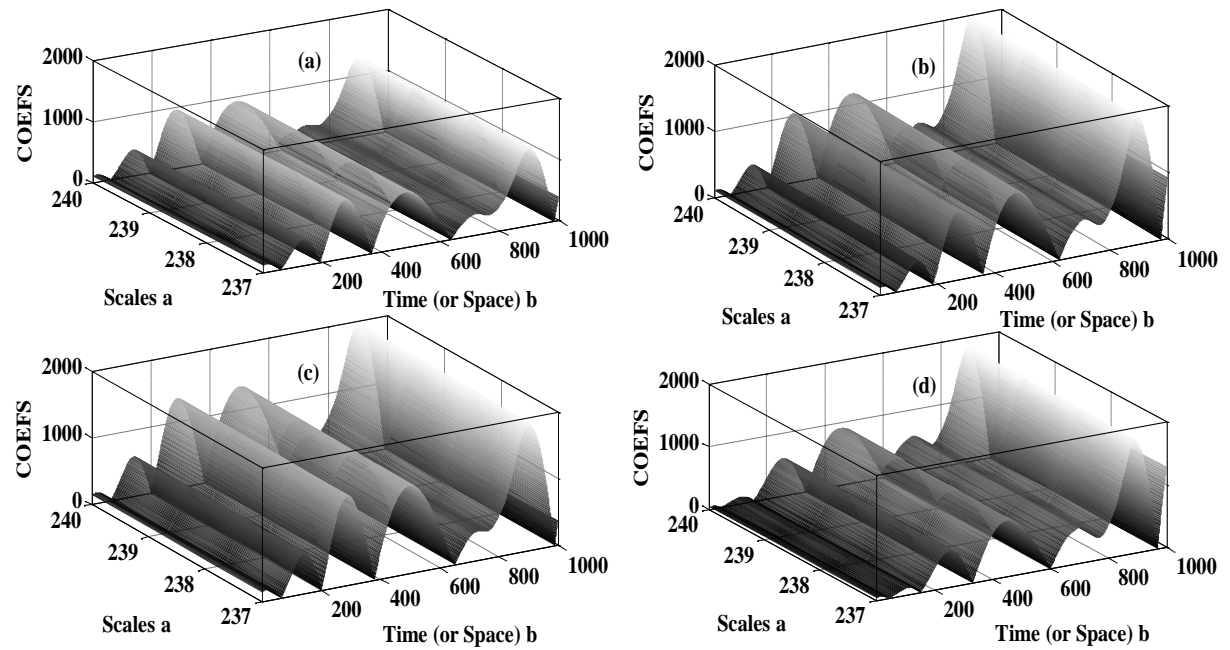

Figure 4. 3D CWT plot for different fault current signals with 'coiflet3' as mother wavelet and in 22 to 25 scale; (a) CWT plot for L-G fault, (b) CWT plot for L-L-G fault, (c) CWT plot for 3ph-G fault, (d) CWT plot for L-L fault.

Figure 4 (a)-(d) represents the 3D CWT coefficient plots for various faults. Here, in these plots, three axes are time (x-axis), scale (y-axis) and coefficients (z-axis). Thus, time localization of the harmonic frequencies with different amplitude occurs.

\section{B. Feature Selection for Detection and Localization Algorithm}

The problem of feature selection is to take a set of candidate features and select a subset that performs the best under some classification system. This procedure can reduce not only the cost of recognition by reducing the number of features that need to be collected, but in some cases, it can also provide better accuracy due to finite sample size effect and lesser training time too. Feature selection needs two parameters.

\section{Attribute evaluator \\ II. Method}

In this case, correlation-based feature selection (CFS) subset evaluator is used for evaluating all the attributes regarding the correlation coefficients and the best-first search algorithm is used for searching the best features among all. Total 120 features (RMS, standard deviation, crest factor, mean, maxima, minima, kurtosis, variance, skewness and median for 3 phases and in four different scales) are initially considered for the detection and localization purpose, which later reduced to 12 (RMS of 3 phases and four different scales) attributes. With the minimization of the total number of attributes by 1/10, the entire training time has also gone down accordingly. This attribute selection was performed in WEKA.

\section{Fault Detection and Faulty Line Detection Results}

When a fault occurs, it is the very much primary thing to identify or detect the fault type to understand the severity of the fault. During the fault, the breaker trips at the feeder end. The current signals captured from the feeder also taken for the further analysis to determine fault type. Initially, CWT coefficients are calculated, and further, the statistical features/attributes (RMS) are derived from the CWT coefficients. Thus, total 12 features/attributes are obtained (i.e., for 3 -phases - four different scales). Four-class fault type classification using 10-fold crossvalidation analysis result is presented in Table 1 . The confusion matrix for classification is shown in Table 2. Figure 5 shows the graphical representation of fault classification clustering plot with ANN. It represents the graphical training result using ANN for fault classification. 
Table 1. Four class fault type classification results using 10 -fold cross-validation

\begin{tabular}{ccc}
\hline (Sampling frequency: 50kHz, fault location: $0,20,30,40,50,60,70,80,90,100 \%$ of the line) \\
\hline $\begin{array}{c}\text { No of data } \\
\text { for each class }\end{array}$ & $\begin{array}{c}\text { Total data in } \\
\text { training set }\end{array}$ & Classification accuracy \\
\hline 7000 & 28000 & $100 \%$ \\
\hline
\end{tabular}

Table 2. Confusion matrix for classification of faults using cross-validation

\begin{tabular}{ccccc}
\hline A & B & C & D & Classified as \\
\hline 7000 & 0 & 0 & 0 & A=L-G \\
0 & 7000 & 0 & 0 & B=L-L-G \\
0 & 0 & 7000 & 0 & C=L-L \\
0 & 0 & 0 & 7000 & D=3ph-G \\
\hline
\end{tabular}

Table 3. Faulty line detection results using 10 -fold cross-validation for the different type of faults

\begin{tabular}{ccccc}
\hline \multicolumn{5}{c}{ ( Sampling frequency: 50kHz, fault location: 10\% of the line) } \\
\hline Fault Type & $\begin{array}{c}\text { No of } \\
\text { healthy } \\
\text { samples }\end{array}$ & $\begin{array}{c}\text { No of } \\
\text { faulty } \\
\text { samples }\end{array}$ & No of attributes & $\begin{array}{c}\text { Classification } \\
\text { accuracy }\end{array}$ \\
\hline L-G & 1700 & 100 & 12 (RMS of CWT & $100 \%$ \\
L-L-G & 1700 & 100 & $\begin{array}{l}\text { coefficients of } \\
\text { 3Phase current }\end{array}$ & $100 \%$ \\
3Ph-G & 1700 & 100 & signals in four & $100 \%$ \\
L-L & 1700 & 100 & scales) & $100 \%$ \\
\hline
\end{tabular}

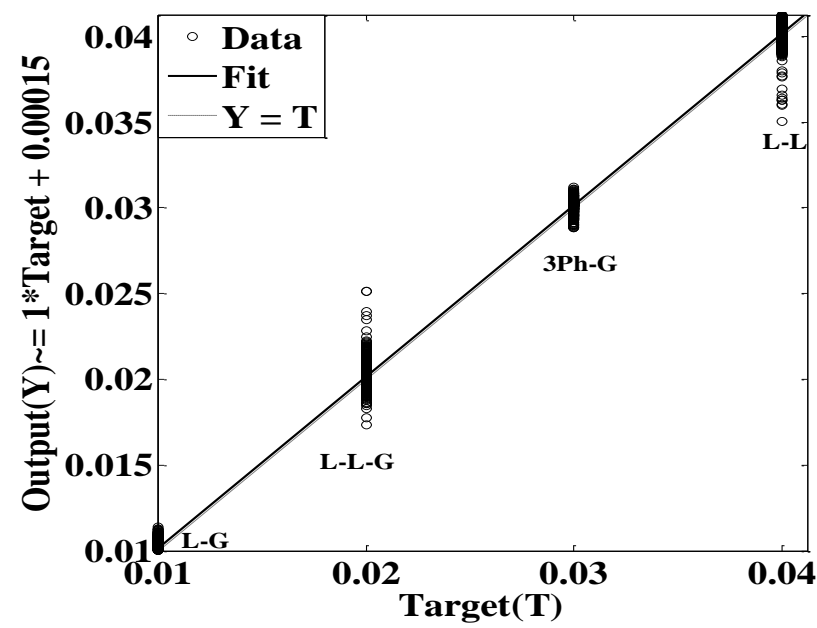

Figure 5. Clustering plot for fault classification using ANN

In fault detection and localization, the sampling frequency is considered $50 \mathrm{kHz}$. However, from the fault detection results, it is evident that the CWT-ANN based algorithm successfully detects the fault type among four different classes. In fault classification, the data used for signal processing and further analysis is captured from the faulty feeder. In the next stage, faulty line detection is very much essential to localize the fault successfully. The signals are recorded from sending-end of all the lines. Captured signals then pass through CWT and the features It shows 
the detailed method, result and the efficiency of the CWT-ANN based algorithm. Thus the overall comparison between [3] and the current study is established. Finally, these features help to detect the faulty line as ANN successfully classifies the faulty line from the healthy line. The line detection result is shown in Table 3.

\section{Fault Localization Results}

The fault localization requires precision in the results, as several impedances based methods are not that accurate in a real scenario. The CWT-ANN based localization algorithm uses the RMS data calculated for different fault scenario for the training of appropriate neural architecture. The different fault scenario consists of different fault, different SSC level, and various location. Table 4 corresponds to the results for fault location with different mother-wavelet and different type of fault. At the end of the analysis using several mother wavelets and ANN it is found that the error (the difference between actual fault distance and the average network output) lies nearly in a range of $1.15 \mathrm{~m}$ to $1.63 \mathrm{~m}$ with Daubechies 4 mother-wavelet, which is reasonably good, compared to the previous studies. The other mother-wavelets 'Coiflet3' and 'Morlet' are also performing well after selecting proper scale. But, the results show the superiority of 'Daubechies' mother-wavelet over others on the basis of performance error.

Table 4. Fault localization results using CWT-ANN based algorithm

\begin{tabular}{|c|c|c|c|c|c|c|}
\hline \multirow{13}{*}{ 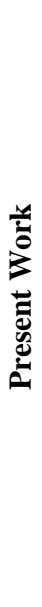 } & $\begin{array}{l}\text { Fault } \\
\text { Type }\end{array}$ & $\begin{array}{l}\text { Mother } \\
\text { Wavelet }\end{array}$ & $\begin{array}{c}\text { FFNN } \\
\text { Architecture }\end{array}$ & $\begin{array}{c}\text { Number } \\
\text { of } \\
\text { Epochs }\end{array}$ & $\begin{array}{c}\text { Performance } \\
\text { Error }\end{array}$ & $\begin{array}{c}\text { Error in } \\
\text { Distance(m) }\end{array}$ \\
\hline & L-G & \multirow{4}{*}{ Morlet } & \multirow{12}{*}{$8: 8: 1$} & 1000 & $1.83 \mathrm{e}-07$ & 1.59 \\
\hline & L-L-G & & & 1000 & $3.44 \mathrm{e}-07$ & 2.16 \\
\hline & L-L & & & 1000 & $1.13 \mathrm{e}-07$ & 1.22 \\
\hline & $3 \mathrm{Ph}-\mathrm{G}$ & & & 1000 & $3.13 \mathrm{e}-07$ & 2.11 \\
\hline & L-G & \multirow{4}{*}{ Coiflet3 } & & 301 & $9.98 \mathrm{e}-08$ & 1.14 \\
\hline & L-L-G & & & 1000 & $1.08 \mathrm{e}-07$ & 1.22 \\
\hline & L-L & & & 174 & $9.87 \mathrm{e}-08$ & 1.20 \\
\hline & $3 \mathrm{Ph}-\mathrm{G}$ & & & 1000 & $1.78 \mathrm{e}-07$ & 1.61 \\
\hline & L-G & \multirow{4}{*}{ Daubechies4 } & & 136 & $9.49 \mathrm{e}-08$ & 1.15 \\
\hline & L-L-G & & & 141 & $9.91 \mathrm{e}-08$ & 1.22 \\
\hline & L-L & & & 139 & $9.41 \mathrm{e}-08$ & 1.23 \\
\hline & $3 \mathrm{Ph}-\mathrm{G}$ & & & 1000 & $1.76 \mathrm{e}-07$ & 1.63 \\
\hline
\end{tabular}
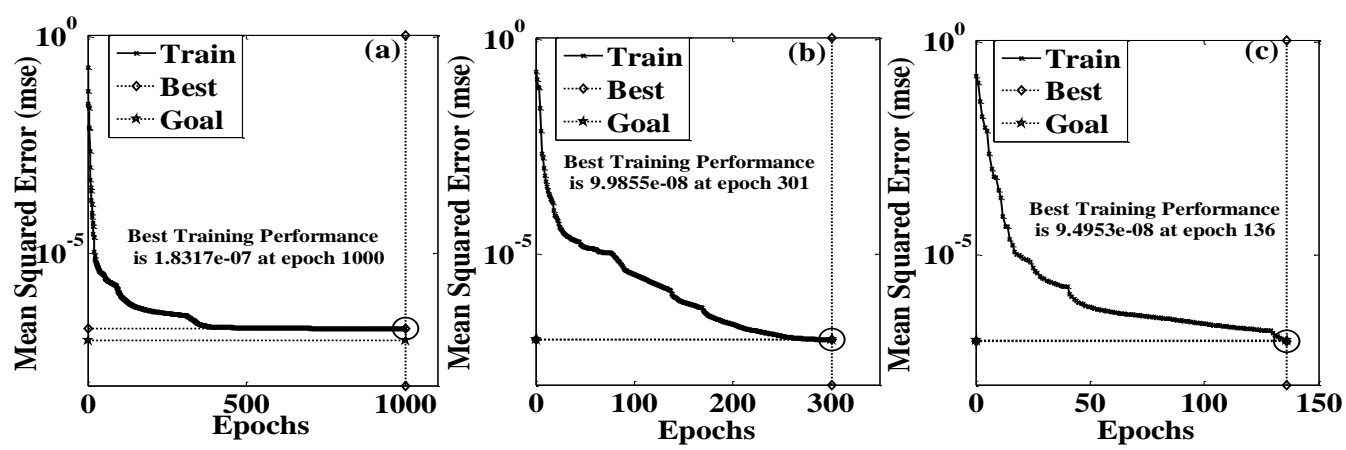

Figure 6. Training performance plot of fault localization using ANN for L-G fault with different mother wavelets; (a) Morlet, (b) Coiflet3, (c) Daubechies4. 

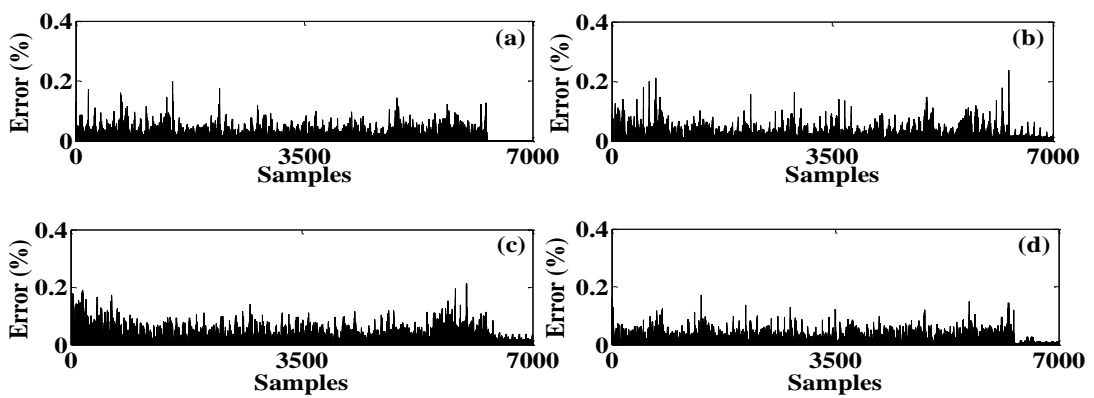

Figure 7. Percentage error plot for localization of fault using "coiflet3" mother wavelet; (a) CWT plot for L-G fault, (b) CWT plot for L-L-G fault, (c) CWT plot for 3ph-G fault, (d) CWT plot for L-L fault.
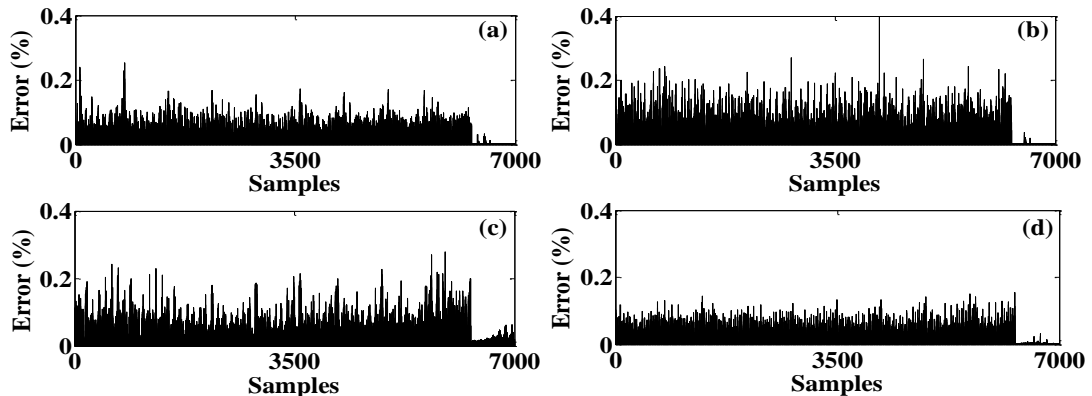

Figure 8. Percentage error plot for localization of fault using "Morlet" mother wavelet; (a) CWT plot for L-G fault, (b) CWT plot for L-L-G fault, (c) CWT plot for 3ph-G fault, (d) CWT plot for L-L fault.
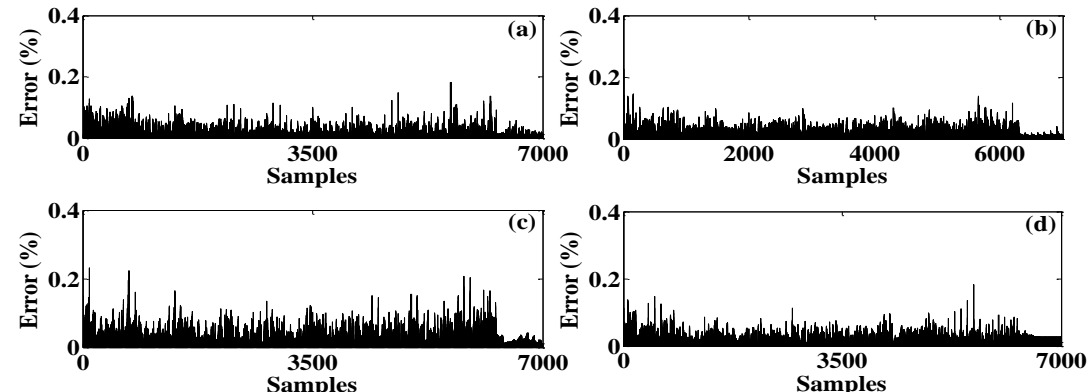

Figure 9. Percentage error plot for localization of fault using "Daubechies4" mother wavelet; (a) CWT plot for L-G fault, (b) CWT plot for L-L-G fault, (c) CWT plot for 3ph-G fault, (d) CWT plot for L-L fault.

Figure 6 depicts the performance plot of the fault localization-training algorithm using ANN for L-G fault with different mother wavelets, and it differentiates between the mother wavelets. Figure. 6 also shows that the training performance with 'Daubechies' and 'Coiflet' motherwavelet is much better compared to other mother wavelets and it is converging in lesser number of iterations. Moreover, Table 5 shows that the difference in method and algorithm can make the improvements in the results. However, in all the cases, the test system is same, but the significant difference in the algorithm is CWT is used as a signal-processing tool in present work. Whereas PCA is used in the literature of [3] as feature extractor. The stationary wavelet transform is used in [4] along with impedance information, path characteristic frequencies (PCFs) used using a traveling wave based method in [5] and 'symlet' wavelet is used in [6]. However, the present CWT-ANN based algorithm comprises better feature extraction and better neural 
Table 5. Qualitative comparison with the previous literature of works

\begin{tabular}{|c|c|c|c|c|c|}
\hline $\begin{array}{c}\text { Basis of } \\
\text { comparison }\end{array}$ & $\begin{array}{c}\text { Thukaram, } \\
\text { Khincha, } \\
\text { and } \\
\text { Vijaynarasi } \\
\text { mha 2005 } \\
{[10]}\end{array}$ & $\begin{array}{c}\text { Salim et al. } \\
2008 \\
{[23]}\end{array}$ & $\begin{array}{l}\text { Pourahmadi- } \\
\text { Nakhli and } \\
\text { Safavi } 2011 \\
\text { [24] }\end{array}$ & $\begin{array}{l}\text { Dhend and } \\
\text { Chile 2017 } \\
\text { [25] }\end{array}$ & $\begin{array}{c}\text { CWT-ANN based } \\
\text { approach (Present } \\
\text { Work) }\end{array}$ \\
\hline $\begin{array}{l}\text { Modelling \& } \\
\text { Data } \\
\text { acquisition }\end{array}$ & $\begin{array}{l}52 \text { - bus } 11 \\
\mathrm{kV} \text { Radial } \\
\text { distribution } \\
\text { system } \\
\end{array}$ & $\begin{array}{l}\text { Distribution } \\
\text { system }\end{array}$ & $\begin{array}{l}\text { 6-bus test } \\
\text { distribution } \\
\text { network }\end{array}$ & $\begin{array}{l}15 \text { bus smart } \\
\text { grid } \\
\text { distribution } \\
\text { system } \\
\end{array}$ & $\begin{array}{l}52 \text { - bus } 11 \mathrm{kV} \text { Radial } \\
\text { distribution system }\end{array}$ \\
\hline \multicolumn{6}{|c|}{ Fault classification } \\
\hline $\begin{array}{l}\text { Domain of } \\
\text { Analysis }\end{array}$ & Time domain & $\begin{array}{l}\text { Time- } \\
\text { frequency } \\
\text { domain }\end{array}$ & Travelling Wave & $\begin{array}{c}\text { Time-frequency } \\
\text { domain }\end{array}$ & Time-frequency domain \\
\hline $\begin{array}{l}\text { Network } \\
\text { Simulation } \\
\text { Variations } \\
\end{array}$ & $\begin{array}{l}\text { SSC level:20 } \\
\text { - 50 MVA }\end{array}$ & N/A & N/A & $\begin{array}{c}\text { Different fault } \\
\text { location, and } \\
\text { fault type }\end{array}$ & $\begin{array}{l}\text { SSC level:20, 25, 30, } \\
35,40,45 \text { and } 50 \text { MVA }\end{array}$ \\
\hline $\begin{array}{c}\text { Signal } \\
\text { Processing }\end{array}$ & N/A & $\begin{array}{l}\text { Stationary } \\
\text { wavelet } \\
\text { transform }\end{array}$ & N/A & $\begin{array}{c}\text { 'Symlet' } \\
\text { discrete WT }\end{array}$ & $\begin{array}{l}\text { CWT with Daubechies4 } \\
\text { is taken as the mother } \\
\text { wavelet. }\end{array}$ \\
\hline $\begin{array}{l}\text { Feature } \\
\text { Extraction }\end{array}$ & $\begin{array}{l}\text { Principal } \\
\text { components }\end{array}$ & $\begin{array}{c}\text { Current } \\
\text { signal's } \\
\text { energy } \\
\text { informatio } \\
\mathrm{n} \\
\end{array}$ & N/A & $\begin{array}{l}\text { Standard } \\
\text { deviation } \\
\text { (STD) of the } \\
\text { coefficient }\end{array}$ & $\begin{array}{l}\text { RMS of CWT } \\
\text { coefficients obtained } \\
\text { from the signals }\end{array}$ \\
\hline $\begin{array}{l}\text { Classifier } \\
\text { Used }\end{array}$ & $\begin{array}{l}\text { SVM and } \\
\text { ANN }\end{array}$ & ANN & N/A & N/A & ANN \\
\hline $\begin{array}{c}\text { Fault } \\
\text { Classification } \\
\text { Result }\end{array}$ & $\begin{array}{l}\text { Correctly } \\
\text { Classified }\end{array}$ & $\begin{array}{l}\text { Correctly } \\
\text { Classified }\end{array}$ & N/A & $\begin{array}{c}\text { Correctly } \\
\text { classified by } \\
\text { STD }\end{array}$ & $\begin{array}{c}\text { SVM: } 100 \% \text { (correctly } \\
\text { classified } \\
\text { instances }: 1800 \text { ) } \\
\text { Cross-Validation } \\
\text { Result: } 100 \% . \\
\end{array}$ \\
\hline \multicolumn{6}{|c|}{ Fault localization } \\
\hline $\begin{array}{l}\text { Domain of } \\
\text { Analysis }\end{array}$ & $\begin{array}{l}\text { Impedance- } \\
\text { based method }\end{array}$ & $\begin{array}{c}\text { Time- } \\
\text { frequency } \\
\text { domain } \\
\end{array}$ & $\begin{array}{c}\text { Time- } \\
\text { frequency } \\
\text { domain } \\
\end{array}$ & $\begin{array}{l}\text { Time-frequency } \\
\text { domain }\end{array}$ & $\begin{array}{l}\text { Time-frequency domain } \\
\text { (CWT) }\end{array}$ \\
\hline $\begin{array}{l}\text { Network } \\
\text { Simulation } \\
\text { Variations }\end{array}$ & $\begin{array}{l}\text { SSC level and } \\
\text { fault } \\
\text { Location. }\end{array}$ & $\begin{array}{c}\text { Different } \\
\text { fault } \\
\text { location, and } \\
\text { fault } \\
\text { resistance, } \\
\text { inception } \\
\text { angle }\end{array}$ & $\begin{array}{l}\text { Different fault } \\
\text { location, fault } \\
\text { resistance, } \\
\text { SSC level, } \\
\text { inception } \\
\text { angle }\end{array}$ & $\begin{array}{l}\text { Different fault } \\
\text { location, and } \\
\text { fault type }\end{array}$ & $\begin{array}{l}\text { SSC level and different } \\
\text { kind of fault is } \\
\text { considered in various } \\
\text { fault location: } 10- \\
100 \% \text { of the line. }\end{array}$ \\
\hline $\begin{array}{c}\text { Signal } \\
\text { Processing }\end{array}$ & PCA & $\begin{array}{l}\text { ANNs and } \\
\text { immune } \\
\text { algorithm } \\
\text { optimization }\end{array}$ & $\begin{array}{c}\text { Wavelet-based } \\
\text { Multiresolutio } \\
\mathrm{n} \text { analysis }\end{array}$ & $\begin{array}{c}\text { 'Symlet' } \\
\text { discrete WT }\end{array}$ & $\begin{array}{l}\text { CWT with Daubechies } 4 \\
\text { is considered as the } \\
\text { mother wavelet. }\end{array}$ \\
\hline $\begin{array}{l}\text { Feature } \\
\text { Extraction }\end{array}$ & $\begin{array}{l}\text { Principal } \\
\text { Component } \\
\text { Analysis } \\
\text { (PCA) }\end{array}$ & $\begin{array}{l}\text { Impedance } \\
\text { Information }\end{array}$ & $\begin{array}{c}\text { Path } \\
\text { characteristic } \\
\text { frequencies } \\
\text { (PCFs) }\end{array}$ & $\begin{array}{l}\text { Standard } \\
\text { deviation of } \\
\text { coefficient }\end{array}$ & $\begin{array}{l}\text { RMS of CWT } \\
\text { coefficients of the } \\
\text { signal. }\end{array}$ \\
\hline $\begin{array}{l}\text { Localization } \\
\text { tool used }\end{array}$ & $\begin{array}{c}\text { SVM, ANN } \\
\text { (Architecture: } \\
3-3-1) \\
\end{array}$ & ANN & ANN & $\begin{array}{l}\text { Fault locating } \\
\text { factor }\end{array}$ & $\begin{array}{c}\text { ANN (Architecture: 8- } \\
8-1 \text { ) }\end{array}$ \\
\hline $\begin{array}{l}\text { Localization } \\
\text { accuracy }\end{array}$ & $\begin{array}{l}\text { ANN: } 100- \\
\text { 300m; SVM } \\
\text { and PCA: } \\
\text { approximatel } \\
\text { y } 10 \mathrm{~m}\end{array}$ & $\begin{array}{l}\text { Localization } \\
\text { Error: } \\
\text { Between } 1 \% \\
\text { and } 7 \% \text {. }\end{array}$ & $\begin{array}{c}\text { The error lies } \\
\text { between } 0.9 \mathrm{~m} \\
-970 \mathrm{~m} .\end{array}$ & $\begin{array}{c}\text { Detects faulty } \\
\text { bus (location) } \\
\text { but does not } \\
\text { give exact fault } \\
\text { location. } \\
\end{array}$ & $\begin{array}{l}\text { Minimum error: } 1.15 \mathrm{~m} \\
\text { Maximum error: } 1.63 \mathrm{~m}\end{array}$ \\
\hline
\end{tabular}

network performance for estimating fault location with lesser performance error. The detailed localization result of for four type of faults are shown in Figure. 7, 8 and 9 that shows the testing error plot for each sample for different mother wavelets. The best average error in 
localization is only $1.15 \mathrm{~m}$ to $1.63 \mathrm{~m}$ with Daubechies 4 mother-wavelet, which proves the efficiency of the proposed algorithm compared to existing impedance based algorithms. Table 5 represents a comparison of the methods as well as results with [3]-[6] as different methods have been applied to the distribution systems to detect and localize faults. Given the comparison, the present study offers better accuracy than others do. The methods used in [4][6] localizes the faulty bus. Moreover, unlike present study, they do not pinpoint the exact fault location accurately.

\section{E. Fault Detection and Localization under Dynamically Changing Load}

The power system is dynamically changing regarding topology, loading, etc. The impact of this change mainly comes due to the dynamically changing load [15]. With the change in load, the steady-state value of the current also varies. Thus, the pattern of the transient also changes for different loading conditions. In this scenario, it is essential to detect and localize fault accurately. In this work, along with SSC level, the load has also been varied, and the performance of fault classification and localization algorithm is recorded. Two types of loading condition considered here are uniformly varying load $(20 \%, 50 \%, 70 \%$, and $100 \%$ of above base load value) in all buses and randomly varying load in all busses. These conditions are taken into account while capturing the signals for ten different locations and 7 SSC level for building training and testing data for ANN.
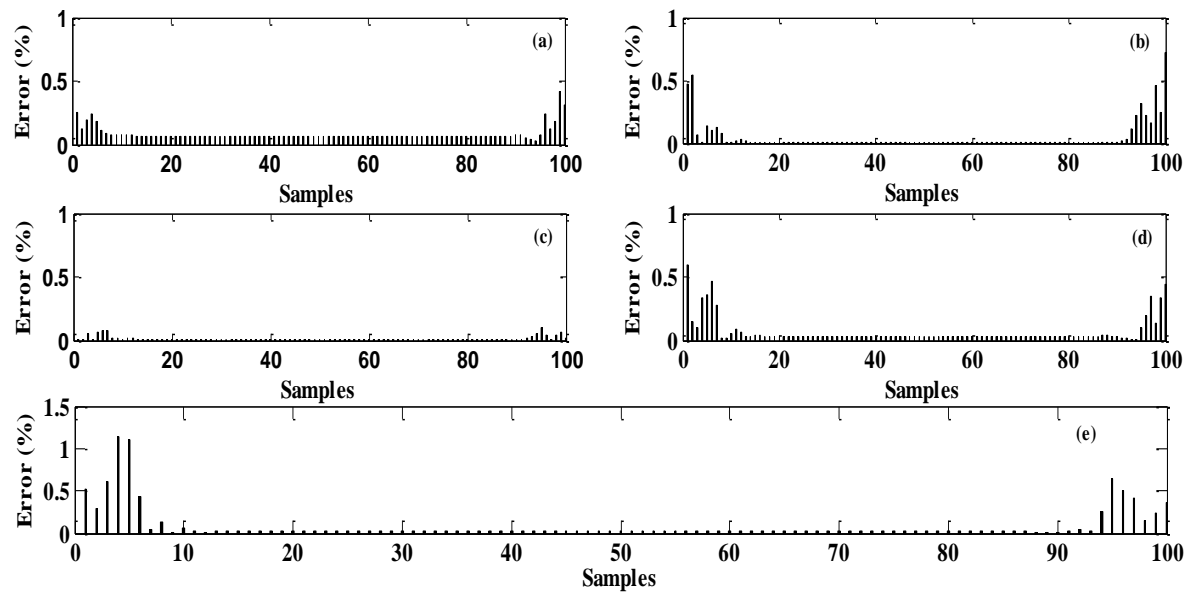

Figure 10. Percentage error plot for fault localization under different load variation; (a) $20 \%$ increase in load (uniform), (b) 50\% increase in load (uniform), (c) $70 \%$ increase in load (uniform), (d) 100\% increase in load (uniform), (e) Non-uniform load variation.

\section{- Uniformly changing load}

The performance of CWT-ANN based fault detection and localization algorithm is shown below. Table 6 shows the classification accuracy for the cross-validation analysis. Figure.10 (a, b, c, d) represents the fault localization accuracy under varying loads condition on the 52-bus system. For classification, there are 400 samples for each type of fault and the Total data in training set is 1600, which gives a classification accuracy of 100\%. In case of localization Figure.10 (a, b, c, d) shows the four testing results for different loading conditions with the result of 100 test samples each. The average testing error in $20 \%, 50 \%, 70 \%$ and $100 \%$ increase in load are $4 \mathrm{~m}$, $2 \mathrm{~m}, 0.5 \mathrm{~m}$ and $3 \mathrm{~m}$ respectively. This is much more accurate than the results reported in the existing works of literature under load variation.

\section{- Randomly changing load}

In practical cases, the system load changes non-uniformly and it is necessary to consider nonuniform load variation in the system while testing the CWT-ANN based algorithm. In this work, 
system load is varied non-uniformly for each bus to build the training data for the neural network. Seven different load data set in which load at each bus is randomly varied is used in this case study. The testing result considering non-uniform load variation is shown in Figure. 10 (e). A total number of training data for the training of ANN is 7000 .

Table 6. Comparison of fault localization results under load variation

\begin{tabular}{|c|c|c|c|c|c|c|c|}
\hline Loading & $\begin{array}{l}\text { Fault } \\
\text { Type }\end{array}$ & $\begin{array}{c}\text { FFNN } \\
\text { Architecture }\end{array}$ & $\begin{array}{c}\begin{array}{c}\text { Number } \\
\text { of } \\
\text { Training } \\
\text { Samples }\end{array} \\
\end{array}$ & $\begin{array}{c}\text { Number } \\
\text { of } \\
\text { Epochs }\end{array}$ & $\begin{array}{c}\text { Best } \\
\text { Performance }\end{array}$ & $\begin{array}{c}\text { Error in } \\
\text { Distance(m) }\end{array}$ & $\begin{array}{l}\text { Computational } \\
\text { Time(sec) }\end{array}$ \\
\hline Normal & & & 1750 & 120 & $9.99 \mathrm{e}-06$ & 5.56 & 2.42 \\
\hline $\begin{array}{c}20 \% \\
\text { increase }\end{array}$ & & & 900 & 60 & $9.46 \mathrm{e}-07$ & 4 & 0.94 \\
\hline $\begin{array}{c}50 \% \\
\text { increase }\end{array}$ & & $5 \cdot 8 \cdot 1$ & 900 & 80 & $9.53 \mathrm{e}-07$ & 2 & 1.20 \\
\hline $\begin{array}{c}70 \% \\
\text { increase }\end{array}$ & L-G & $5: 8: 1$ & 900 & 113 & $7.74 \mathrm{e}-07$ & 0.5 & 1.60 \\
\hline $\begin{array}{c}100 \% \\
\text { increase }\end{array}$ & & & 900 & 226 & $9.94 \mathrm{e}-07$ & 3 & 3.06 \\
\hline $\begin{array}{c}\text { No- } \\
\text { Uniform }\end{array}$ & & & 7000 & 500 & $3.047 \mathrm{e}-05$ & 4.45 & 26.91 \\
\hline
\end{tabular}

In Table 6, the performance of CWT-ANN based algorithm under different load variation is shown, which shows the ability of the algorithm in working under randomly load variation. In case of randomly changing load, the number of training samples required is much higher than other cases. It also needs more iteration for achieving the performance goal, thus, resulting more computational time. The computational time would not be an issue as several high-performance processors are available which are capable of reducing the computational time.

\section{Conclusion}

In the problem of fault classification, time-frequency domain response is efficiently working to discriminate the faults in much lesser computational time. Here, among all features, the most crucial feature is found to be RMS, which offers a better accuracy for both detection and localization. This algorithm provides a very efficient scheme to detect and localize faults in radial distribution systems. With a good percentage of accuracy in detection, this algorithm has also minimized the localization error between $1.15 \mathrm{~m}$ and $1.63 \mathrm{~m}$ with "Daubechies4" motherwavelet, which is a much better result as compared to the results reported in the similar works with other mother wavelets. The proposed CWT-ANN algorithm also gives promising in load varying conditions. This algorithm provides $100 \%$ classification accuracy for both fault type detection and the faulty line detection. The testing results describe the superiority of the algorithm as it successfully detects and localizes the faults with a minimum error margin. However, there is an ample amount of future scope in this field of research, which will emphasize the reduction of errors considering more parameters and computational burden in the localization fault in distribution systems.

\section{References}

[1]. S. M. Amin and B. F. F. Wollenberg, "Toward a smart grid: power delivery for the $21 \mathrm{st}$ century," IEEE Power and Energy Magazine, vol. 3, no. 5, pp. 34-41, 2005.

[2]. A. Borghetti, M. Bosetti, M. Di Silvestro, C. A. Nucci, and M. Paolone, "Continuouswavelet transform for fault location in distribution power networks: Definition of mother wavelets inferred from fault originated transients," IEEE Trans. Power Syst., vol. 23, no. 2, pp. 380-388, 2008.

[3]. D. Thukaram, H. P. Khincha, and H. P. Vijaynarasimha, "Artificial neural network and support vector machine approach for locating faults in radial distribution systems," IEEE Trans. Power Deliv., vol. 20, no. 2 I, pp. 710-721, 2005. 
[4]. R. H. Salim, K. R. C. de Oliveira, A. D. Filomena, M. Resener, and A. S. Bretas, "Hybrid fault diagnosis scheme implementation for power distribution systems automation," IEEE Trans. Power Deliv., vol. 23, no. 4, pp. 1846-1856, 2008.

[5]. M. Pourahmadi-Nakhli and A. A. Safavi, "Path characteristic frequency-based fault locating in radial distribution systems using wavelets and neural networks," IEEE Trans. Power Deliv., vol. 26, no. 2, pp. 772-781, 2011.

[6]. M. H. Dhend and R. H. Chile, "Fault diagnosis of smart grid distribution system by using smart sensors and symlet wavelet function," J. Electron. Test., vol. 33, no. 3, pp. 329-338, 2017.

[7]. C. Fukui and J. Kawakami, "An expert system for fault section estimation using information from protective relays and circuit breakers," IEEE Power Eng. Rev., vol. PER6, no. 10, pp. 29-30, 1986.

[8]. C. K. Jung, K. H. Kim, J. B. Lee, and B. Klöckl, "Wavelet and neuro-fuzzy based fault location for combined transmission systems," Int. J. Electr. Power Energy Syst., vol. 29, no. 6, pp. 445-454, 2007.

[9]. C. S. Chang, L. Tian, and F. S. Wen, "A new approach to fault section estimation in power systems using ant system," Electr. Power Syst. Res., vol. 49, no. 1, pp. 63-70, 1999.

[10]. P. K. Dash and S. R. Samantaray, "A novel distance protection scheme using timefrequency analysis and pattern recognition approach," Int. J. Electr. Power Energy Syst., vol. 29, no. 2, pp. 129-137, 2007.

[11]. P. S. Bhowmik, P. Purkait, and K. Bhattacharya, "A novel wavelet assisted neural network for transmission line fault analysis," Proc. INDICON 2008 IEEE Conf. Exhib. Control. Commun. Autom., vol. 1, no. 5, pp. 223-228, 2008.

[12]. R. Polikar, “The Wavelet Tutorial," Comp. A J. Comp. Educ., vol. 17, pp. 1-14, 2009.

[13]. P. Purkait and S. Chakravorti, "Wavelet transform-based impulse fault pattern recognition in distribution transformers," IEEE Trans. Power Deliv., vol. 18, no. 4, pp. 1588-1589, 2003.

[14]. M. Mirzaei, M. Z. a A. Kadir, E. Moazami, and H. Hizam, "Review of fault location methods for distribution power system," Aust. J. Basic Appl. Sci., vol. 3, no. 3, pp. 26702676, 2009.

[15]. J. Mora, J. Meléndez, M. Vinyoles, J. Sánchez, and M. Castro, “An overview to fault location methods in distribution system based on single end measures of voltage and current," in International Conference on Renewable Energies and Power Quality (ICREPQ'04), 2004, vol. 1, no. 2, pp. 235-239.

[16]. M. M. Saha, R. Das, P. Verho, and D. Novosel, "Review of fault location techniques for distribution systems," in Power Systems and Communications Infrastructures for the future, 2002, no. September, pp. 1-6.

[17]. A. Yadav and A. Swetapadma, "A single ended directional fault section identifier and fault locator for double circuit transmission lines using combined wavelet and ANN approach," Int. J. Electr. Power Energy Syst., vol. 69, pp. 27-33, 2015.

[18]. S. A. Saleh, C. R. Moloney, and M. Azizur Rahman, "Implementation of a dynamic voltage restorer system based on discrete wavelet transforms," Power Deliv. IEEE Trans., vol. 23, no. 4, pp. 2366-2375, 2008.

[19]. S. R. Samantaray, P. K. Dash, and G. Panda, "Fault classification and location using HStransform and radial basis function neural network," Electric Power Systems Research, vol. 76. pp. 897-905, 2006.

[20]. H. F. Zhang, Z. C. Pan, and Z. G. Tian, "Detection and location of ground faults using a discernible signal," in Proceedings of the IEEE Power Engineering Society Transmission and Distribution Conference, 2005, vol. 2005, pp. 1-4.

[21]. H. Yong, C. Minyou, and Z. Jinqian, "High impedance fault identification method of the distribution network based on discrete wavelet transformation," in 2011 International Conference on Electrical and Control Engineering, 2011, pp. 2262-2265. 
[22]. K. Figureueiredo, J. a. Moor Neto, L. Lovisolo, J. C. dos Santos Rocha, and L. de Menezes Laporte, "Location of faults generating short-duration voltage variations in distribution systems regions from records captured at one point and decomposed into damped sinusoids," IET Gener. Transm. Distrib., vol. 6, no. 12, pp. 1225-1234, 2012.

[23]. H. Lala and S. Karmakar, "Continuous wavelet transform and artificial neural network based fault diagnosis in 52 bus hybrid distributed generation system," in IEEE Students Conference on Engineering and Systems (SCES), 2015, 2015, pp. 1-6.

[24]. S. G. Mallat, "Multifrequency channel decompositions of images and wavelet models," IEEE Trans. Accoustic, Speech Signal Process., vol. 37, no. 12, 1989.

[25]. Stephane G. Mallat, "A theory for multiresolution signal decomposition: The wavelet representation," IEEE Trans. Patern Anal. Mach. Intell., vol. 11, no. 7, pp. 674-693, 1989.

[26]. Ingrid Doubenchies, "The wavelet transform , time-frequency localization and signal analysis," IEEE Trans. Inf. Theory, vol. 36, no. 5, 1990.

[27]. O. Rioul and M. Vetierli, "Wvelets and signal processing," IEEE Signal Process. Mag., vol. 8, no. 4, pp. 14-38, 1991.

[28]. D. E. Rumelhart, G. E. Hinton, and R. J. Williams, "Learning representations by backpropagating errors," Nature, vol. 323, no. 6088, pp. 533-536, 1986.

[29]. P. J. Werbos, "Beyond regression: New tools for prediction and analysis in the behavioral sciences," MIT Press, 1974.

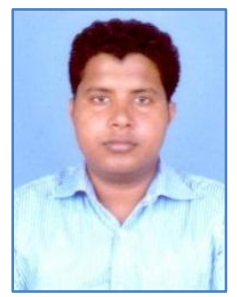

Himadri Lala was born in Suri, India, on $27^{\text {th }}$ October, 1987. He received his Bachelor's degree in electrical engineering from West Bengal University of Technology, India, in 2010. He received the M.E. degrees from Indian Institute of Engineering, Science, and Technology (IIEST), Shibpur \{Formerly, Bengal Engineering and Science University $\}$ in 2012. Currently he is a Ph.D. Research Scholar at the Department of Electrical Engineering, NIT Rourkela, India. His research interests include Detection and localization of power system transients using various signal processing and soft computing techniques.

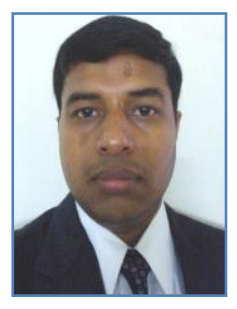

Subrata Karmakar was born in Balarampur, India, in 1981. He received the Bachelor's degree (with honors) in electrical engineering from the University of Burdwan, Bardhaman, India, in 2004, and the M.Tech. and Ph.D. degrees from the National Institute of Technology (NIT), Durgapur, India, in 2006 and 2011, respectively. He is currently an Assistant Professor with the Department of Electrical Engineering, NIT, Rourkela, India. His research interests include online monitoring of high-voltage power system equipment, detection of fault using signal processing and soft computing technique.

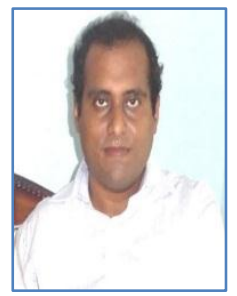

Sanjib Ganguly was born on in India in 1981. He obtained Bachelor of Engineering degree in Electrical Engineering from Indian Institute of Engineering, Science, and Technology (IIEST), Shibpur \{Formerly, Bengal Engineering and Science University $\}$ in 2003. He received Master of Electrical Engineering degree from Jadavpur University, Kolkata in 2006. He was awarded with the Ph.D degree from the Department of Electrical Engineering, Indian Institute of Technology Kharagpur in 2011. He worked in the Tata Power Company Ltd., as a Sr. officer, electrical maintenance of $2 \times 500 \mathrm{MW}$ thermal power units in Trombay Thermal Power Station, Mumbai from 2006-2007. He worked as the Assistant Professor in NIT Rourkela from 2011-2015. He is presently working as Assistant Professor in Indian Institute of Technology Guwahati from 2015. His research interest includes distribution system planning and optimization, multi-objective optimization, and evolutionary algorithms. 